\title{
Interdisciplinaridade e processos de ensino e aprendizagem: experiências formativas de docentes que lecionam matemática
}

\section{Interdisciplinarity and teaching and learning processes: formative experiences of teachers who teach mathematics}

\author{
Matias Neto Alves Ferreira ${ }^{1 *}$, Antônio Roberto Xavier ${ }^{1}$, Wendel Melo Andrade ${ }^{2}$, Maria José \\ Costa dos Santos ${ }^{2}$
}

\begin{abstract}
RESUMO
O presente artigo tem o objetivo de compreender como a formação acadêmica inicial tem contribuído para a realização de práticas interdisciplinares nos processos de ensino e aprendizagem da matemática. Para tanto buscamos analisar a dialética existente sobre o conceito de interdisciplinaridade em conjunto com outras disciplinaridades, nos fundamentando em teóricos como Pombo (2004), Fazenda (2008) e outros. Metodologicamente, o estudo se assenta com mais ênfase na abordagem qualitativa, e seu delineamento se deu com uma revisão de literatura, com a identificação dos sujeitos e a aplicação de questionários semiestruturados. Os resultados encontrados apontam para uma polissemia referente ao conceito de interdisciplinaridade, e que embora as práticas interdiciplinares no âmbito da formação inicial se mostrem significativa, percebemos que ainda há uma necessidade de se ampliar o trabalho com estas práticas no ensino superior. A aproximação com os professores revelou o reconhecimento da interdisciplinaridade como uma importante referência para pôr em prática os saberes matemáticos relacionando-os com outras áreas do conhecimento.
\end{abstract}

Palavras-chave: Interdisciplinaridade; Matemática; Ensino e aprendizagem; Docentes.

\section{ABSTRACT}

This article aims to understand how initial academic training has contributed to the realization of interdisciplinary practices in the teaching and learning processes of mathematics. Therefore, we seek to analyze the existing dialectic on the concept of interdisciplinarity together with other disciplinarities, based on theorists such as Pombo (2004), Fazenda (2008) and others. Methodologically, the study is based with more emphasis on a qualitative approach, and its design was based on a literature review, with the identification of subjects and the application of semi-structured questionnaires. The results found point to a polysemy regarding the concept of interdisciplinarity, and that although interdisciplinary practices in the scope of initial training are significant, we realize that there is still a need to expand the work with these practices in higher education. The approach with teachers revealed the recognition of interdisciplinarity as an important reference for putting into practice mathematical knowledge relating it to other areas of knowledge.

Keywords: Interdisciplinarity; Math; Teaching and learning; Teachers.

\footnotetext{
${ }^{1}$ Universidade da Integração Internacional da Lusofonia Afro-brasileira (UNILAB)

*E-mail: matias.gti.1209@gmail.com

${ }^{2}$ Universidade Federal do Ceará (UFC)
} 


\section{INTRODUÇÃO}

A docência, metaforicamente, é algo mágico e, ao mesmo tempo, prático e realístico. É também vista como a arte do encantamento, nos fazendo adimirar os conhecimentos que são ensinanados. Todos aqueles que detêm a essência do magistério e têm o prazer de ensinar, são como mágicos, que se utilizam da sua criatividade para prover o espetáculo da aprendizagem, fomentando em seus discentes a importância do conhecimento, a consciencia da cidadania e a humanização do saber.

No entanto, o exercício da docência guarda também desafios e dificuldades. Nesse contexto, uma das problemáticas presentes na educação é a fragmentação do conhecimento em "caixinhas" cada vez menores. Isso se iniciou a partir da necessidade dos estudiosos de se especializarem em uma área, reforçando a fragmentação do que é ensinado e do que é aprendido.

Essa compartimentalização do conhecimento deu origem ao que hoje é conhecido como disciplinas, áreas do saber que se distanciam cada vez mais umas das outras. Assim, quem estuda algo específico não consegue se soltar de determinadas amarras e, caso seja colocado em outra área do saber, não consegue desenvolver um bom trabalho, em decorrencia das limitações teóricas e práticas relacionadas a este novo conhecimento.

Esse problema se agrava quando é direcionado para a área das ciências exatas e, principalmente, para assuntos que envolvem cálculos, como a matemática. Essa dificuldade ocorre em sentido de mão dupla, pois muitos matemáticos não se sentem à vontade em desbravarem outra área do conhecimento, assim como docentes de outras áreas possuem dificuldades em trabalhar com a matemática.

Essa problemática não ocorre exclusivamente com a matemática. É um efeito que acontece também com outras áreas do conhecimento. Isso faz com que as disciplinas se distanciem umas da outras, tornando os saberes individualizados e compartimentados fazendo com que os elos que existem entre as disciplinas não sejam percebidos.

Os argumentos supracitados nos fazem levantar o seguinte questionamento: Como a formação acadêmica inicial tem contribuído para a realização de práticas interdisciplinares nos processos de ensino e aprendizagem pelos professores de matemática?

Muitas vezes a dificuldade no aprendizado da matemática, pelos discentes, está associada a áreas psico-cognitivas, como o déficit de atenção, a baixa autoestima, a impulsividade, a dificuldade de leitura e até problemas com habilidades sociais. A matemática tem uma linguagem e uma representação específica e particular. Assim, o saber matemático requer, muitas vezes, uma determinada contextualização para que seja compreendido.

Visto essa dificuldade de aprendizado da matemática e o distanciamento desta ciência das demais áreas do conhecimento, podemos minimizar estas problemáticas com o uso da interdisciplinaridade, pois, conforme Fazenda (1994, 2008), nela há uma busca pela justaposição 
dos saberes, uma vez que nenhuma área da ciência deve se sobressair em relação a outra. Sob um olhar trivial, podemos dizer que a interdisciplinaridade é o entrecruzamento dos diversos fios que formam os conceitos básicos das ciências ou de qualquer outro tipo de conhecimento.

Fazenda (2008), em seus estudos sobre interdisciplinaridade, destaca que esse termo deriva de um conjunto de relações entre as áreas do conhecimento, visando sempre uma contínua relação do saber atrelada a novas relações de conteúdo, tornando o ensino interdisciplinar algo mais esclarecedor.

Desse modo, a interdisciplinaridade quando praticada como uma metodologia de ensino, não deve ser apenas aplicada como um tema transversal e sim de forma integrativa e como agente ativo dentro da práxis educativa, aprimorando sua didática de forma positiva. Nessa perspectiva, o docente visa buscar conceitos mais próximo da realidade do aluno e que podem se interrelacionar com o conteúdo didático, resultando em um melhor ensino e, consequentemente, numa melhor aprendizagem (FAZENDA, 2008).

Contudo, a interdisciplinaridade pode ser um aporte didático para o professor, pois, diagnosticando as preferências dos alunos, ele poderá relacionar os conteúdos matemáticos com conceitos de outras áreas de interesse dos estudantes.

Partindo dessa conjectura, o presente artigo tem o objetivo de compreender, a partir da visão de professores de matemática dos anos finais do ensino fundamental de uma escola do Ceará, como a formação acadêmica inicial tem contribuído para a realização de práticas interdisciplinares nos processos de ensino e aprendizagem desta ciência.

Metodologicamente esta pesquisa se desenvolveu a partir das experiências dos sujeitos e de suas compreensões sobre elas. Quanto à forma de abordagem do problema, privilegiamos a análise qualitativa (MINAYO, 2010).

Ao levantarmos discussões sobre a temática interdisciplinaridade, apesar desse tema não ser algo novo, buscamos contribuir para uma melhor compreensão deste conceito e principalmente com o fomento a esta prática dentro da sala de aula.

\section{A DIALÉTICA INTERDISCIPLINAR E SUAS DISCIPLINARIDADES}

A interdisciplinaridade vem ganhando destaque na comunidade científica, desde os anos de 1920. Conforme Fazenda (1994), os paradigmas da interdisciplinaridade começaram a ganhar complexidade na Europa, principalmente na França e na Itália, por volta dos anos 1960, como resultado de movimentos estudantis que reivindicavam um ensino mais voltado para as questões de ordem social, política e econômica da época, dado que as interações dos saberes poderiam, segundo seu entendimento, resolver problemas sociais.

Para uma discussão plausível sobre interdisciplinaridade e tudo o que está a sua volta, é necessário compreender, de forma clara, o que são as disciplinaridades, evidenciando as 
diferenças e distinções existentes entre os conceitos de multidisciplinaridade, pluridisciplinaridade, interdisciplinaridade e transdisciplinaridade.

As áreas de conhecimento podem se inter-relacionar em níveis de complexidade de formas distintas. Para Garrutti e Santos (2014), a fragmentação dos saberes de forma compartimentalizada foi evidenciada a partir da necessidade de especializar o conhecimento dos profissionais em decorrência da industrialização da sociedade.

Percebemos que os saberes disciplinares, conhecidos como multidisciplinaridade, pluridisciplinaridade, interdisciplinaridade e transdisciplinaridade, relacionam-se com momentos históricos vividos pela humanidade e demonstram, em termos teóricos e práticos, o reconhecimento e a problematização da complexidade das variações e interações entre as diferentes áreas ou disciplinas.

Pinheiro (2006) esclarece que os níveis de interação assinalam as áreas do conhecimento sob diferentes aspectos, partem de uma ingênua transferência de teorias a uma diluição de fronteiras entre os campos científicos envolvidos. Já Pombo (2004) elucida que existe uma série de acontecimentos que se desenvolvem, a partir de um ponto em comum, de tal modo que, na composição dos conhecimentos, seriam colocados em arranjos paralelos de um determinado ponto de vista.

A disciplinaridade é um conjunto de conhecimentos que se relacionam (ou não) de maneira intrínseca para a compreensão do saber científico, de acordo com Morin (2002), o termo disciplina se caracteriza como um relacionamento dos conhecimentos científicos, emergindo, a partir disso, uma diversificação nas especialidades do que é conhecido, e resultando em um afunilamento ou fragmentação dos saberes. Em parte, essa especialização do conhecimento se faz necessária. No entanto, especializar-se não significa compartimentalizar-se ou se colocar dentro de "caixas" que impedem uma visão mais ampla dos fenômenos e que não permitem um diálogo entre os diferentes saberes.

Entendemos que a especialização do saber pode, de algum modo, ter um aspecto negativo quando colocada numa forma geral da visão dos saberes, pois, o processo de afunilamento do conhecimento faz com que o indivíduo não se permita enxergar outras formas de pensar, enclausurando-se, segundo Fazenda (2008), em uma caixa individualizada de conhecimento e interagindo apenas com aqueles que também fazem parte de sua "caixinha", de modo que todo mundo que está fora dela se torna algo estranho e desconhecido.

Com isso, percebemos que cada nível de inter-relação do conhecimento tem sua complexidade e sua forma de pensar. Assim, nos pontos a seguir são elucidados os principais níveis de justaposição do conhecimento, baseados em autores como Japiassu (1976), Pombo (2004), Pinheiro (2006), Carlos (2007) e Fazenda (2008): 
- Multidisciplinaridade: É uma forma de conhecimento que está atrelada à estrutura tradicional do currículo das escolas, algo corriqueiro nas salas de ensino, voltada a preceitos de um só nível ou de objetivos únicos, com a inexistência de algum relacionamento entre os sujeitos e/ou conhecimentos. A sua característica fundamental é o relacionamento de ideias entre disciplinas, no caso um conjunto de conteúdos ensinados de forma simultânea, mas não existindo justaposição do saber.

- Pluridisciplinaridade: É o nível disciplinar que tem uma justaposição de variadas disciplinas, atreladas a um único nível de conhecimento, evidenciando as relações existentes entre si, destacando as similaridades entre os conhecimentos de uma determinada área com as demais. Nesse nível, não é necessário o envolvimento de questionamentos complexos. No caso, faz-se necessária a existência de um relacionamento entre as disciplinas, mas de forma simples.

- Interdisciplinaridade: Esse nível de disciplinaridade, de forma resumida, é entendido como um leque de disciplinas que se associam umas com as outras em um mesmo nível focal, com objetivos múltiplos condizentes a uma única finalidade. Contudo, ele será contextualizado de uma melhor forma ao longo deste texto.

- Transdisciplinaridade: É, nos níveis hierárquicos das disciplinaridades, a mais recente, a qual demonstra um entendimento do conhecimento além do que se pode ver no nível (inter)disciplinar, sendo algo novo e abstrato para uma justaposição dos saberes, que almejam explorar áreas do saber que nunca foram desbravadas. Essa disciplinaridade é entendida como uma ordem de fusão unificada, pois transcende as fronteiras disciplinares.

Com efeito, a interdisciplinaridade está em vários campos do saber, como a política, a tecnologia e a economia (THIESEN, 2008). Entretanto, quando o enfoque interdisciplinar é na educação o termo se relaciona a um contexto mais vasto e complexo, num movimento dialético em que professor e aluno se entrelaçam, para que, segundo Tavares (2008), descrevam juntos um caminho traçado com novas atitudes, novas investigações, novos projetos e novos saberes.

Fazenda (2008, p. 161) elucida que a:

[...] palavra interdisciplinaridade evoca a "disciplina" como um sistema constituído ou por constituir, e a interdisciplinaridade sugere um conjunto de relações entre disciplinas abertas sempre a novas relações, que se vai descobrindo. Interdisciplinar é toda interação existente de duas ou mais disciplinas no âmbito do conhecimento, dos métodos e da aprendizagem. Interdisciplinaridade é o conjunto das interações existentes e possíveis das disciplinas nos âmbitos indicados. 
Em conformidade com Yared (2008), a significação do termo interdisciplinaridade está relacionada a algo que não está parado. E segundo Gusdorf (1990, p. 2), ela “[...] invoca também um espaço comum, um fator de coesão entre saberes diferentes”, percebendo que esse nível disciplinar está presente desde o início do entendimento conceitual até as fronteiras desse mesmo conhecimento.

A partir do efeito da compartimentalização de conhecimento que as envolve, as ciências trazem consigo uma gama de críticas postas à racionalidade técnica. Esse efeito discursivo, segundo Morin (2002), vem da necessidade de defender o reconhecimento distinto entre as epistemologias, ou seja, a partir de algo comum é possível arquitetar diversos meios para abordar fenômenos de maneira mais complexa.

A complexidade é um aliado da interdisciplinaridade, e, para isso, o seu entendimento não se atrela a outro apenas de forma linear, mas se enraíza de forma radicular entre os saberes, trazendo, a todo momento, algo novo e surpreendente para aquele conhecimento que, até então, era dito como estagnado.

Com esse enfoque e a partir dos estudos desenvolvidos por Carlos (2007), podemos perceber que a interdisciplinaridade é um campo de vários significados, no caso, um saber polissêmico. Abaixo, no quadro 1, foram elencadas algumas ressignificações sobre o termo interdisciplinaridade.

Quadro 1 - Polissemia da interdisciplinaridade

\begin{tabular}{|c|l|}
\hline Termo Interdisciplinar & \multicolumn{1}{|c|}{ Ressignificação } \\
\hline Interdisciplinaridade Heterogênea & $\begin{array}{l}\text { Movimento enciclopédico, conhecimento fragmentado } \\
\text { que se aproxima da multidisciplinaridade. }\end{array}$ \\
\hline Pseudo-interdisciplinaridade & $\begin{array}{l}\text { Uso de instrumentos neutros (teorias, métodos) } \\
\text { aplicáveis a diversas disciplinas, sendo que essa } \\
\text { neutralidade não representa o aporte necessário para } \\
\text { gerir conceitos interdisciplinares. }\end{array}$ \\
\hline Interdisciplinaridade auxiliar & $\begin{array}{l}\text { Emprego de métodos e teorias de uma ciência em outra. } \\
\text { No caso, conceitos de uma disciplina podem auxiliar a } \\
\text { outra, algo que se assemelha à relação biológica } \\
\text { interespecífica, chamada de comercialismo, a qual se } \\
\text { utiliza do outro para se beneficiar sem que o outro se } \\
\text { prejudique }\end{array}$ \\
\hline Interdisciplinaridade compósita & $\begin{array}{l}\text { Caráter utilitário, visualizada no meio social, como } \\
\text { política, saúde e/ou economia. Voltado para a solução } \\
\text { de problemas específicos ou de situações concretas para } \\
\text { uma determinada população, como a erradicação de } \\
\text { uma determinada epidemia. }\end{array}$ \\
\hline Interdisciplinaridade unificadora & $\begin{array}{l}\text { Um tipo de justaposição do saber de forma muito } \\
\text { interespecífica, que resulta no surgimento de um novo } \\
\text { campo científico (ou disciplina) do saber. Por exemplo, } \\
\text { a associação da química com a biologia originou a } \\
\text { bioquímica. }\end{array}$ \\
\hline
\end{tabular}




\begin{tabular}{|c|l|}
\hline Interdisciplinaridade complementar & $\begin{array}{l}\text { Sobreposição dos conhecimentos em algumas } \\
\text { especialidades, os quais se entrelaçam em um mesmo } \\
\text { objetivo de estudo. } \\
\text { É } \text { E conhecimento interdisciplinar mais tradicional, pois } \\
\text { visa à busca de um saber mais absoluto. Esse é o método } \\
\text { que mais se aproxima da transdisciplinaridade, pois tem } \\
\text { um sentido filosófico mais utópico }\end{array}$ \\
\hline $\begin{array}{c}\text { Quando é usada como um instrumento de decisão ou } \\
\text { Interdisciplinaridade administrativa } \\
\text { ou externa }\end{array}$ & $\begin{array}{l}\text { planejamento. Por exemplo, tem-se a elaboração de um } \\
\text { currículo de uma determina escola, que, } \\
\text { equivocadamente, usa o termo interdisciplinaridade } \\
\text { para transparecer, dentro do documento, um princípio } \\
\text { mediador de comunicação entre as variadas disciplinas }\end{array}$ \\
\hline Interdisciplinaridade de geometria \\
variável & $\begin{array}{l}\text { Engloba a Interdisciplinaridade auxiliar e a composta. } \\
\text { Isso ocorre quando uma ciência busca o auxílio em } \\
\text { outras ciências para a exploração e o aprimoramento } \\
\text { dos seus conceitos. Por exemplo, tem-se a história } \\
\text { quando usa dados da arqueologia para compor um } \\
\text { determinado assunto. }\end{array}$ \\
\hline
\end{tabular}

Fonte: Carlos (2007, p. 54)

Fazendo referência ao quadro acima e à gama de significados que tem a interdisciplinaridade, percebemos a necessidade de diferenciar as ações interdisciplinares quando se faz alusão à pesquisa científica das que existem no âmbito do ensino. Podemos entender o conceito de interdisciplinaridade de forma conglomerada quando ele:

[...] considera o fato trivial de que todo conhecimento mantém um diálogo permanente com outros conhecimentos, diálogo que pode ser de questionamento, de confirmação, de complementação, de negação, de ampliação, de iluminação de aspectos não distinguidos (BRASIL, 2013, p. 75).

Assim constatamos que a interdisciplinaridade é o momento em que ocorre uma correlação entre duas ou mais disciplinas, em que uma depende da outra para a existência de um diálogo pertinente entre os assuntos tratados, e para que o conhecimento seja estudado de forma mais clara e coerente.

\section{MÉTODOS, TÉCNICAS E PROCEDIMENTOS PARA COLETA E ANÁliSE dOS DADOS}

Nesta pesquisa priorizamos o método de análise qualitativa, pois, a partir da fala dos professores buscamos interpretar como a interdisciplinaridade se fundamenta na formação da identidade docente. Para tanto, buscamos conhecer como sua formação acadêmica tem contribuído na realização de práticas interdisciplinares no ensino da matemática (GIL, 2008; MINAYO, 2010). 
Desse modo, este método de análise nos permite diagnosticar melhor como a interdisciplinaridade é compreendida e assimilada por esses professores e como eles a utilizam em suas prática docentes.

Os sujeitos desta pesquisa são professores que lecionam matemática nos anos finais do ensino fundamental. Uma vez que os educadores que lecionam nesta etapa de escolarização devem possuir uma licenciatura ou uma habilitação atuando em uma área específica (BRASIL, 1996). Embora, segundo o Instituto Nacional de Estudos e Pesquisas Educacionais Anísio Teixeira (INEP), ainda existam, no Brasil, professores que não atuam unicamente em sua área de formação (BRASIL, 2017).

Após a aproximação com os professors de uma determina escola de ensino fundamental do estado do Ceará, aptos a participarem da pesquisa, foram selecionados oito que lecionam a disciplina de matemática, aos quais a pesquisa foi apresentada, em um momento de planejamento. Contudo, apenas quatro professores se voluntariaram a dar continuidade à pesquisa.

A ferramenta utilizada para coleta de dados foi um questionário semiestruturado com 11 questões (abertas e fechadas), que possibilitou um melhor estreitamento entre os referências teóricos citadas anteriormente e os escritos dos professores. O referido questionário foi subdividido em três blocos de perguntas: o bloco I abordou os dados pessoais; o bloco II retratou as concepções e práticas interdisciplinares no curso de licenciatura dos sujeitos; e o bloco III focou nas suas concepções e práticas profissionais.

Os passos metodológicos adotados nesta pesquisa foram esquematizados da seguinte forma: (1) iniciamos com uma revisão de literatura, com vistas à compreensão ampla do fenômeno estudado à luz de estudos publicados em diferentes espaços de produção acadêmica; (2) procedemos com a identificação do lócus e dos sujeitos da pesquisa; (3) seguimos com a elaboração e aplicação do questionário semiestruturado, o qual possibilitou, na investigação, uma análise mais aproximada sobre a realidade dos sujeitos pesquisados, visualizando como a formação acadêmica tem contribuído para a realização de práticas interdisciplinares nos processos de ensino e aprendizagem da matemática.

\section{ANÁlISE DAS EXPERIÊNCIAS FORMATIVAS DOS PROFESSORES DE MATEMÁTICA}

Partindo das respostas dos professores discutimos elementos relativos a suas experiências formativas e análise de suas práticas interdisciplinares.

Na busca por entender a percepção dos sujeitos desta pesquisa sobre a sua concepção de interdiciplinaridade, ao serem questionados sobre o que é interdiciplinaridade, foram obtidas, entre outras respostas, as seguintes informações: 
P1: Quando se trabalha o conceito de outras disciplinas dentro da matemática ou vice-versa.

P2: Quando há o uso de outras disciplinas, de forma contextualizada, para introduzir e ministrar determinado conteúdo, a exemplo da matemática.

P3: É quando duas ou mais disciplinas conversam entre si, e uma permeia a outra.

Percebemos pelos comentários dos docentes que há, entre os sujeitos, uma limitação na compreensão deste conceito, pois sabemos que interdisciplinaridade não se restringe apenas a relação entre duas ou mais disciplinas. Afinal, ela é mais do que apenas relacionar as disciplinas entre si.

A percepção dos sujeitos investigados denota o aspecto da fragmentação dos saberes, enfatizado por Garrutti e Santos (2014), uma vez que ainda se evidenciam elementos que denotam a compartimentalização do conhecimento, principalmente quando os sujeitos investigados reconhecem que os conceitos e conteúdos são trabalhados disciplinarmente.

Percebemos também uma aproximação do depoimento dos professores com o pensamento de Fazenda (2008), o qual retrata que em uma "caixinha" de conhecimento existe a facilidade de interagir com aqueles que fazem parte de um mesmo campo do saber. Isto é perceptível no caso das disciplinas de áreas afins.

Entretanto, o sujeito P4, demonstrando que as práticas interdisciplinares se configuram numa justaposição de saberes, comentou que: "Ela é entendida como uma relação entre duas ou mais disciplinas, com o mesmo foco, uma dando suporte à outra" (P4).

Nesta fala, percebemos um melhor entendimento sobre o tema, no qual o sujeito ilustra, mesmo que de forma simplificada, que a interdisciplinaridade não é apenas uma relação, mas sim uma justaposição dos saberes, em que uma necessita da outra para o pleno entendimento de um assunto.

Esse pensamento vai ao encontro dos estudos levantados por Pombo (2004), Pinheiro (2006) e Fazenda (2008), que enfatizam uma abordagem desse conceito em que se percebem os níveis de inter-relação e justaposição do conhecimento entre as áreas do saber, que dialogam, de forma interdisciplinar.

É valioso lembrar que, quando apenas relacionamos as disciplinas sem que se necessite resolver problemas complexos, temos segundo a concepção de Japiassu (1976) e Fazenda (1994) a pluridisciplinaridade. Pombo (2004) por sua vez, reafirma que a interdisciplinaridade não se trata apenas de relacionar as disciplinas, pois consiste também em buscar resolver problemas e questionamentos que apenas uma área do saber não conseguiria solucionar.

A cerca das concepções e prátias interdiciplinares quando indagados sobre a existência das discussões interdisciplinares no curso de licenciatura, a maioria dos sujeitos responderam que esta abordagem foi limitada. Mesmo que a Lei de Diretrizes e Bases da Educação Nacional (LDB) (BRASIL, 1996) e as Diretrizes Curriculares Nacionais Gerais da Educação (DCN) (BRASIL, 
2013) apontem que a formação inicial do docente deve conter tais discussões, no âmbito do ensino superior, ainda se evidencia a compartimentalização do conhecimento, por vezes, com os profissionais ainda engaiolados em suas áreas epistemológicas, deixando as demais à margem de sua ação didática.

Ao se indagar os sujeitos desta pesquisa se, no curso de licenciatura, existiu alguma disciplina destinada aos estudos interdisciplinares. Nas analise constatamos que apenas um participante respondeu que sim. E isso nos levanta reflexões que reforçam que no sistema educacional brasileiro a fragmentação do saber em especialidades compartimentadas ainda é algo presente no ensino superior.

Entretanto, foi destacado pelos sujeitos que embora haja uma necessidade de se ampliar as práticas interdicipinares no ensino superior, os momentos em que foram oportunizadas ações interdiciplinares na formação inicial dos docentes investigados, estas se mostraram significativa para a sua formação profissional, lhe proporcionando um olhar diferenciado sobre a sua didática.

Algo sempre ilustrado por Fazenda (2008) é que a interdisciplinaridade é uma prática que traz o ensino para a realidade do aluno e, conseguintemente, melhora o seu aprendizado.

Quando indagados se suas ações metodológicas eram pautadas na interdisciplinaridade, alguns dos sujeitos responderam que apenas em parte, e quando solicitados a justificarem o questionamento, responderam que:

\footnotetext{
P1: Em matemática, algumas vezes, mas, dependendo do conteúdo, não é possível.

P2: Em parte, pois não é em todas as aulas que me utilizo do auxílio de outras disciplinas para ministrar os conteúdos de matemática.

P4: Não são todos os conteúdos que necessitam de outras áreas do conhecimento para terem fortalecida sua prática.
}

Nas falas dos sujeitos, como podemos perceber, ocorre certa confusão entre os conceitos de interdisciplinaridade e pluridisciplinaridade, pois é recorrente o discurso de que alguns assuntos da matemática não necessitam de outra disciplina para elucidar seus conhecimentos. Isso torna evidente que os respondentes entendem interdisciplinaridade como relacionar disciplinas. No entanto, fazer interdisciplinaridade não é apenas relacionar a matemática com a história, por exemplo. Esse entendimento vai além do simples relacionamento. É necessário compreendermos que interdisciplinaridade requer que os conhecimentos de áreas distintas se aproximem e cooperem mutuamente.

Quando questionados sobre suas áreas de atuação, eles responderam que atualmente trabalham apenas com a matemática, mas que já lecionaram outras disciplinas no decorrer de sua carreira docente. Isso reflete uma realidade do sistema educacional brasileiro, pois, segundo demonstram dados do INEP (BRASIL, 2017), 60\% dos profissionais atuam em áreas disciplinares diferentes daquelas para as quais são licenciados/habilitados. 
Ao serem indagados se eles acreditavam que uma maior abordagem de práticas interdisciplinares nos cursos licenciatura poderia auxiliariar no desenvolvimento do sistema educacional, eles responderam que sim, e justificaram que poderia tornar o ensino mais contextualizado, pois, possibilitaria uma maior aproximação da matemática com outras áreas do conhecimento e também com a realidade dos alunos.

\section{CONSIDERAÇÕES FINAIS}

Fazer interdisciplinaridade consiste, ao mesmo tempo, numa consonância e numa partilha de saberes entre duas ou mais áreas do conhecimento, buscando uma na outra, conceitos, regras e teorias que expliquem o que está sendo estudado. Levantando com isso uma visão holística do saber e fortalecendo as conexões existentes entre as ciências, sem que ocorra a fragmentação do conteúdo ou da metodologia.

Como já discutinos na introdução deste artigo, educar é uma arte do encantamento em que o professor deve instigar o aluno a sempre querer saber e sempre buscar ampliar seu espectro de conhecimento. Isso não é, obviamente, uma tarefa fácil, o caminho é árduo e, às vezes, doloroso. Portanto, devemos estar sempre aperfeiçoando nossas metodologias para que as aulas de matemática não caiam no modismo ou no conformismo, algo que, às vezes, se torna recorrente quando perdemos o ânimo de exercer o magistério com plenitude.

Os estudos aqui levantados nos fazem refletir que os educadores devem primar por estratégias de ensino que dinamizem o trabalho pedagógico, e, talvez, a interdisciplinaridade possa ser o "pontapé" inicial para esse dinamismo docente, não como um meio único e exclusivo para se ensinar, mas como uma estratégia que minimize a fragmentação do conhecimento.

Conforme foi abordado neste trabalho, ser interdisciplinar é relacionar assuntos na sua total naturalidade prezando pelo diálogo entre áreas distintas na busca de um caráter intelectual com a unificação plena do conhecimento.

Desse modo, podemos concluir que um íntegro desenvolvimento interdisciplinar coexiste com uma relação dialógica entre os saberes, relação esta em que os saberes estão claramente abertos para o intercâmbio do conhecimento, priorizando o processo de ensinar e aprender, pois, no contexto da interdisciplinaridade todos os sujeitos são mestres e aprendizes nesse universo de ensinamentos.

Por fim, concluimos que a interdisciplinaridade no ensino e aprendizagem da matemática se configura como uma prática didático-pedagógica que pode contribuir na superação dos obstáculos epstemológicos da ação docente e principalmente na integração dos saberes entre as diversas áreas do conhecimento, cabendo as instâncias do ensino superior investirem cada vez mais em ações e práticas metodologicas de cunho interdiciplinar para uma melho qualificação da formação inicial do educador. 


\section{REFERÊNCIAS}

BRASIL, Ministério da Educação. Lei n. 9.394, de 20 de dezembro de 1996. Lei de diretrizes e bases da educação nacional - LDB. Diário Oficial da União. Brasília, 23 dez. 1996.

BRASIL, Ministério da Educação. Diretrizes Curriculares Nacionais Gerais da Educação - DCN. Brasília, 2013.

BRASIL, Ministério da Educação. Censo escolar da educação básica - 2016: notas estatísticas. Brasília: INEP, 2017.

CARLOS, Jairo Gonçalves. Interdisciplinaridade no ensino médio: desafios e potencialidades. 2007. 172 f. Dissertação. Mestrado em Ensino de Ciências, Universidade de Brasília, Brasília, 2007.

FAZENDA, Ivani Catarina Arantes. Interdisciplinaridade: história, teoria e pesquisa. 4. ed. Campinas: Papirus, 1994.

FAZENDA, Ivani Catarina Arantes. O Que é interdisciplinaridade?. 202 p. São Paulo: Cortez, 2008.

GARRUTTI, Érica Aparecida; SANTOS, Simone Regina dos. A interdisciplinaridade como forma de superar a fragmentação do conhecimento. Revista RIC - FFC, [s/l.], v. 4, n. 2, 26 nov, p.187-197, 2014.

GIL, Antônio Carlos. Métodos e técnicas de pesquisa social. 6. ed. São Paulo: Atlas, 2008.

GUSDORF, Georges. Reflexions sur leinterdisciplinarité. Bulletin de Psychologie, XLIII, 397, p. 847-868, 1990.

JAPIASSU, Hilton. Interdisciplinaridade e patologia do saber. Rio de Janeiro: Imago, 1976.

MINAYO, Maria Cecília de Souza (Org.). Pesquisa social: teoria, método e criatividade. 29. ed. (Coleção temas sociais). Petrópolis, RJ: Vozes, 2010.

MORIN, Edgar. Os sete saberes necessários à educação do futuro. 6. ed. São Paulo: Cortez, 2002.

POMBO, Olga. Interdisciplinaridade: ambições e limites. Lisboa: Relógio d'Água, 2004.

PINHEIRO, Lena Vania Ribeiro. Ciência da informação: desdobramentos disciplinares, interdisciplinaridade e transdisciplinaridade. São Paulo: UFF, 2006. 
TAVARES, Maria Augusta. Os fios (in)visíveis da produção capitalista: informalidade e precarização do trabalho. 216 p. São Paulo: Cortez, 2008.

THIESEN, Juares da Silva. A interdisciplinaridade como um movimento articulador no processo ensino-aprendizagem. Revista Brasileira de Educação, v. 13, n. 39, 2008.

YARED, Ivone. O que é interdisciplinaridade? In: FAZENDA, Ivani Catarina Arantes. O Que é interdisciplinaridade? Cap. 12, p. 161. São Paulo: Cortez, 2008.

Recebido em: 10/01/2022

Aprovado em: 12/02/2022

Publicado em: 15/02/2022 